\title{
BMJ Open Raising awareness for dementia risk reduction through a public health campaign: a pre-post study
}

\author{
Irene Heger (D) , ${ }^{1}$ Sebastian Köhler, ${ }^{1}$ Martin van Boxtel, ${ }^{1}$ Marjolein de Vugt, ${ }^{1}$ \\ KlaasJan Hajema, ${ }^{2}$ Frans Verhey, ${ }^{1}$ Kay Deckers ${ }^{1}$
}

To cite: Heger I, Köhler S, van Boxtel M, et al. Raising awareness for dementia risk reduction through a public health campaign: a pre-post study. BMJ Open 2020;10:e041211. doi:10.1136/ bmjopen-2020-041211

- Prepublication history and additional material for this paper is available online. To view these files, please visit the journal online (http://dx.doi.org/10. 1136/bmjopen-2020-041211).

Received 04 June 2020 Revised 27 August 2020 Accepted 19 October 2020

Check for updates

(C) Author(s) (or their employer(s)) 2020. Re-use permitted under CC BY-NC. No commercial re-use. See rights and permissions. Published by BMJ.

${ }^{1}$ Alzheimer Centrum Limburg, Department of Psychiatry and Neuropsychology, School for Mental Health and Neuroscience, Maastricht University, Maastricht, The Netherlands

${ }^{2}$ GGD Zuid Limburg, Heerlen, The Netherlands

Correspondence to

Drs Irene Heger;

irene.heger@

maastrichtuniversity.nl and

Dr Kay Deckers;

kay.deckers@

maastrichtuniversity.nl

\section{ABSTRACT}

Objectives Evaluate the effect of a health promotion campaign aimed at increasing awareness about dementia risk reduction in middle-aged community-dwelling individuals in the Netherlands.

Design A 10-month public health campaign using mass media and community participation, supported by eHealth. Population-level difference in awareness before and after the campaign, including variation between demographic groups, was assessed in two independent cross-sectional samples from the same target population.

Setting The public health campaign was launched in the Province of Limburg, the Netherlands, targeting all inhabitants aged $40-75$ years old. Three specific districts within the Province were chosen for an additional community participation approach, in which local stakeholders were invited to support the campaign. Results No pre- $(n=590)$ post- $(n=602)$ difference was observed in people agreeing to the statement that dementia risk reduction is possible $\left(X^{2}(1)=1.27, p=0.260\right)$. For the individual lifestyle factors, physical activity $(7.6 \%$ increase $\left.\left(X^{2}(1)=7.48, p=0.006\right)\right)$ and healthy diet $(10.5 \%$ increase $\left.\left(X^{2}(1)=12.37, p \leq 0.001\right)\right)$ were identified more often as being protective against dementia after the campaign. Of all risk/protective factors assessed, cognitive activity was identified most often at both preassessment (79.4\%) and postassessment (80.4\%), but there was no increase in awareness $\left(X^{2}(1)=0.17, p=0.677\right)$. Selfreported exposure to the campaign was associated with greater awareness and motivation for behavioural change $\left(X^{2}(1)=6.52, p=0.011\right)$. Compared with mass media only, the addition of community participation resulted in better recognition of campaign material and the eHealth platform. Conclusions This study was not able to reach a population-level increase of awareness of dementia risk reduction. Two out of the three lifestyle factors that formed the foundation of the campaign were identified more often after the campaign. Those reported having been exposed to the campaign were more aware and more inclined towards behavioural change.

\section{INTRODUCTION}

Dementia is characterised by progressive decline of cognitive abilities, leading to interference in daily living. Alzheimer's disease (AD) and vascular dementia are the most common underlying pathologies, and often

\section{Strengths and limitations of this study}

This study used extensive precampaign and postcampaign surveys, with large independent samples from the same target population and comparable methodology.

- The public health campaign was designed in consultation with health promotion experts (i.e. municipal health services, Department of Health Promotion of Maastricht University, the Netherlands) and had a flexible design that made it possible to include local stakeholders during the campaign and alter strategies along the way.

- A positive approach was chosen for this health promotion campaign, for example, by using the words 'brain health' and 'room for improvement' to raise awareness of dementia risk reduction, instead of focusing on unhealthy behaviours that increase the risk of dementia.

- The samples were drawn from people from a previous survey study who indicated their interest in future research, which could have led to selection bias (e.g. an overestimation of dementia risk reduction literacy).

- The reach and effect of the campaign was limited due to restrained resources of the research team to reach out to relevant stakeholders and due to a limited budget to cover (mass) media costs (e.g. advertisement in newspapers, billboards).

coexist. ${ }^{1}$ Due to the ageing population, the number of people living with dementia worldwide is expected to triple from 50 million in 2018 to 152 million in $2050 .^{2}$ This rapid global increase and the absence of a curative treatment exposes a major public health concern.

Primary prevention of dementia through lifestyle modification is gaining increasing attention in research and policy. ${ }^{13-5}$ Population-based estimations show that around one-third of all dementia cases might be attributable to seven lifestyle and health-related factors, including physical inactivity, depression and low mental stimulation. ${ }^{4}$ Reducing exposure to these risk factors by $10 \%-20 \%$ per decade would lower the 
prevalence of $\mathrm{AD}$ by as much as $8 \%-15 \%$. ${ }^{4}$ These insights have led to a series of randomised controlled trials (RCTs) using lifestyle interventions to delay or prevent cognitive decline and dementia onset. ${ }^{6-9}$ Neither the multidomain Prevention of Dementia by Intensive Vascular Care trial in 3454 patients aged 70-79 years with known vascular risk factors nor the Multidomain Alzheimer Preventive Trial in 1680 adults aged 70 years and older resulted in significant reduction of incident dementia ${ }^{7}$ and change in memory function, ${ }^{8}$ or only in subgroups. In contrast, the population-based Finnish Geriatric Intervention Study to Prevent Cognitive Impairment and Disability (FINGER), starting earlier in those aged 60-77 years, was the first large-scale RCT that showed beneficial effects on cognition. ${ }^{610}$ It seems that dementia risk reduction interventions should target people in mid-life to minimise lifetime accumulation of risk factor exposure and consequent brain pathology. ${ }^{11-13}$

Recently, a global initiative aimed at harmonising intervention studies on risk factor modification was launched, called World Wide FINGERS (WW-FINGERS). ${ }^{11}$ Incorporated trials include the US Study to Protect Brain Health Through Lifestyle Intervention to Reduce Risk (US POINTER) and the Singapore Intervention Study to Prevent Cognitive Impairment and Disability (SINGER). ${ }^{11}$ The ambition of WW-FINGERS to find robust evidence for lifestyle interventions that delay or prevent dementia onset is promising from a public health perspective. In addition, epidemiological studies have shown decreasing incidence of dementia in high-income countries, observed in several cohorts, ${ }^{14-16}$ probably because of improved cardiovascular health, nutrition and education over the last decades. ${ }^{2}$ The timeliness of dementia prevention interventions was also emphasised by the publication of guidelines for risk reduction of cognitive decline and dementia by the WHO in $2019^{5}$ and the 2020 report of the Lancet Commission on Dementia Prevention, Intervention and Care. ${ }^{17}$

It must, however, be noted that the general public is still largely unaware of the potential of dementia risk reduction, let alone of specific actions to reduce dementia risk. ${ }^{18-21}$ In our own survey among middle-aged adults $(\mathrm{n}=590), 44 \%$ were aware of dementia risk reduction, and only $20 \%-25 \%$ considered vascular conditions to increase the risk. ${ }^{18}$ Hence, despite the need for conclusive RCTs, little is known about how knowledge can be translated to the general public to raise awareness, and how to engage hard-to-reach subgroups (e.g. low health literacy or socioeconomic status) who are often underrepresented in clinical trials, too. ${ }^{22-24}$ Creating risk awareness at the population level is a crucial first step before behaviour change programmes can be developed and implemented.

Dementia awareness campaigns have focused on topics as improving recognition of dementia, ${ }^{25}$ dementia care, ${ }^{26}$ decreasing public stigma ${ }^{27} 28$ and few on dementia risk reduction. ${ }^{29} 30$ An Australian study using an informative website on dementia risk reduction resulted in increased knowledge and motivation to engage in relevant health behaviours. However, no population-level measurements for evaluation were used and the study only included a postintervention assessment of people visiting the website. $^{29}$ One population-based national awareness campaign in Ireland found a significant increase in people agreeing that 'there are things you can do to reduce your risk'. However, awareness of dementia risk reduction was not associated with recognition of the advertisements used during the campaign. ${ }^{30}$

The goal of this study was to evaluate the impact of a health promotion campaign aimed at increasing awareness about dementia risk reduction in middle-aged Dutch community-dwelling individuals. Specifically, we tested change in the level of awareness at the population level before and after the campaign, variation between demographic groups, the effect of different approaches (mass media vs additional community participation) and the use of eHealth supportive technology, in order to distil the lessons learnt for future campaigns and policies.

\section{METHODS}

\section{Target population}

The target population were inhabitants of the Province of Limburg, the Netherlands, aged 40-75 years (558 535 people in total). ${ }^{31}$

\section{Awareness campaign}

The primary aim of this campaign (March 2018 to January 2019) was to increase awareness on dementia risk reduction. The secondary aim was to motivate people for behavioural change by means of eHealth. The campaign was developed by the Alzheimer Centre Limburg at Maastricht University and Maastricht University Medical Centre+, in consultation with the Dutch Municipal Health Services (MHS) and the Department of Health Promotion of Maastricht University. An agency for strategy and design developed the campaign materials and website. ${ }^{32}$ To maximise acceptance in the relatively young target population, a positive phrasing was chosen for the slogan ('We are our own medicine'), terminology (e.g. 'brain health' rather than 'dementia') and campaign material visualising the three campaign themes: 'eat healthy', 'exercise regularly' and 'stay curious' (see online supplemental file 1 for examples). The campaign materials were discussed with stakeholders (Dutch Alzheimer's Association and an evaluation panel of potential end users). We deliberately designed the campaign in a way that would address different people. We provided both a low-level and free app with short, simple text messages that appeared automatically on a daily basis, and provided an extensive website for background information and references to extra literature (e.g. website Dutch Alzheimer's Association). Two different campaign approaches were chosen in order to compare the outcome. A broad campaign was launched, targeting the public via mass media such as newspapers and social media (hereafter "population 
sample'). Three specific districts within the Province (Landgraaf-Schaesberg, Brunssum-Oost and RoermondHoogvonderen) were chosen based on varying socioeconomic status, from low to middle high, and absence of other public health projects (hereafter 'district sample'). We worked together with key figures and facilities in that district, in order to meet the specific needs and wishes of that district.

\section{The eHealth platform}

An online platform called MijnBreincoach ('MyBraincoach') was developed together with two software companies and made available as a mobile app and web portal to the general public during the campaign. ${ }^{33}$ Users complete a '12-item quick test' using the well-validated Lifestyle for Brain Health (LIBRA) score. ${ }^{34}$ This predictive model consists of 12 modifiable risk and protective factors for dementia (e.g. smoking, physical inactivity, depression), and gives people insight into their personal dementia risk profile. Detailed information can be found in online supplemental file 2.

\section{Precampaign and postcampaign surveys}

Two cross-sectional surveys were performed: one precampaign (September 2017 $7^{18}$ ) and one postcampaign (February 2019). The precampaign and postcampaign surveys took place in independent samples, in order to ensure that the potential increase in awareness was not caused by learning effects. The methodology and results of the precampaign survey have been described in more detail elsewhere. ${ }^{18}$

\section{Recruitment process}

The population samples were drawn by the MHS from participants of a previous national health survey ('Gezondheidsmonitor 2016) who had agreed to be contacted for future studies. A random selection of people (40-75 years) was invited to participate via email. The district samples were drawn from the municipal registry by the municipality or by the MHS, based on zip codes and age and received a postal letter.

\section{Measurements}

Age, sex, marital status, educational level, self-reported knowledge of dementia and awareness of dementia risk reduction were assessed both at the preassessment and postassessment. Ten items from the British Social Attitudes (BSA) survey ${ }^{19}$ were used, translated into Dutch. To assess all 12 factors from the LIBRA index,${ }^{34}$ custommade items were also included. ${ }^{18}$ The postcampaign survey included additional items concerning exposure to the campaign (e.g. asking participants whether they recognised campaign material). The items on exposure to the campaign were placed after the items assessing awareness, thereby not influencing one's perspective on the possibility of dementia risk reduction. See online supplemental file 3 for the complete precampaign and postcampaign surveys. The primary outcome of awareness of dementia risk reduction was assessed as the difference between preassessment and postassessment in the proportion of people rejecting the statement 'There is nothing I can do to reduce my dementia risk'. We presented this statement in the Results section in a positive form for reasons of clarity ('dementia risk reduction is possible'). Secondary outcomes were changes in endorsement of the three campaign themes: physical activity, cognitive activity and healthy diet.

\section{Statistical analyses}

Independent group t-tests and $\mathrm{X}^{2}$ tests were used to analyse differences between the precampaign and postcampaign samples, and between population and district samples, and to investigate differences in the relation between sociodemographic variables and level of awareness and knowledge of risk and protective factors. Analyses were performed in Stata V.13.1 (StataCorp, College Station, Texas, USA), with the level of significance set at $\mathrm{p} \leq 0.05$ in two-tailed tests.

\section{Patient and public involvement}

There were no patients involved in this research. Members of the public were involved in the design and roll-out of the public health campaign.

\section{RESULTS}

\section{Demographics}

The response rates of the precampaign and postcampaign surveys were highly comparable (population precampaign $53.6 \%$, postcampaign $54.8 \%$; district precampaign $33.2 \%$, postcampaign $32.2 \%$ ). See online supplemental files 4 and $5 \mathrm{~A}, \mathrm{~B}$ for flow charts of the recruitment process. Table 1 shows the characteristics of the total and the two separate samples. The characteristics of the districts can be found in online supplemental file 6 . The total preassessment sample was highly comparable with the total postassessment sample. As expected by design, the population sample was more highly educated than the district sample at the preassessment $\left(\mathrm{X}^{2}(2)=29.57, \mathrm{p} \leq 0.001\right)$ and postassessment $\left(\mathrm{X}^{2}(2)=17.41, \mathrm{p} \leq 0.001\right)$. An overview of the forms of community engagement is displayed in box 1 .

\section{Exposure to the campaign}

Of all postcampaign participants ( $\mathrm{n}=602), 20.0 \%$ reported to have heard of the campaign, $19.7 \%$ of the slogan, $21.8 \%$ about the eHealth platform and $29.8 \%$ recognised one of the campaign materials (e.g. poster, flyer). Women heard more often about the eHealth platform $(27.5 \%$ vs $\left.16.3 \% ; \mathrm{X}^{2}(1)=9.75, \mathrm{p}=0.002\right)$ and recognised campaign material more often $\left(34.0 \%\right.$ vs $25.8 \% ; \mathrm{X}^{2}(1)=4.23$, $\mathrm{p}=0.040)$ compared with men. Lower educated participants recognised campaign material more often than more highly educated participants did $(33.5 \%$ vs $25.1 \%$; $\left.\mathrm{X}^{2}(1)=4.28, \mathrm{p}=0.039\right)$.

\section{Difference in level of awareness before and after the campaign (total sample)}

Figure 1 displays a precampaign and postcampaign comparison of the percentage of participants 


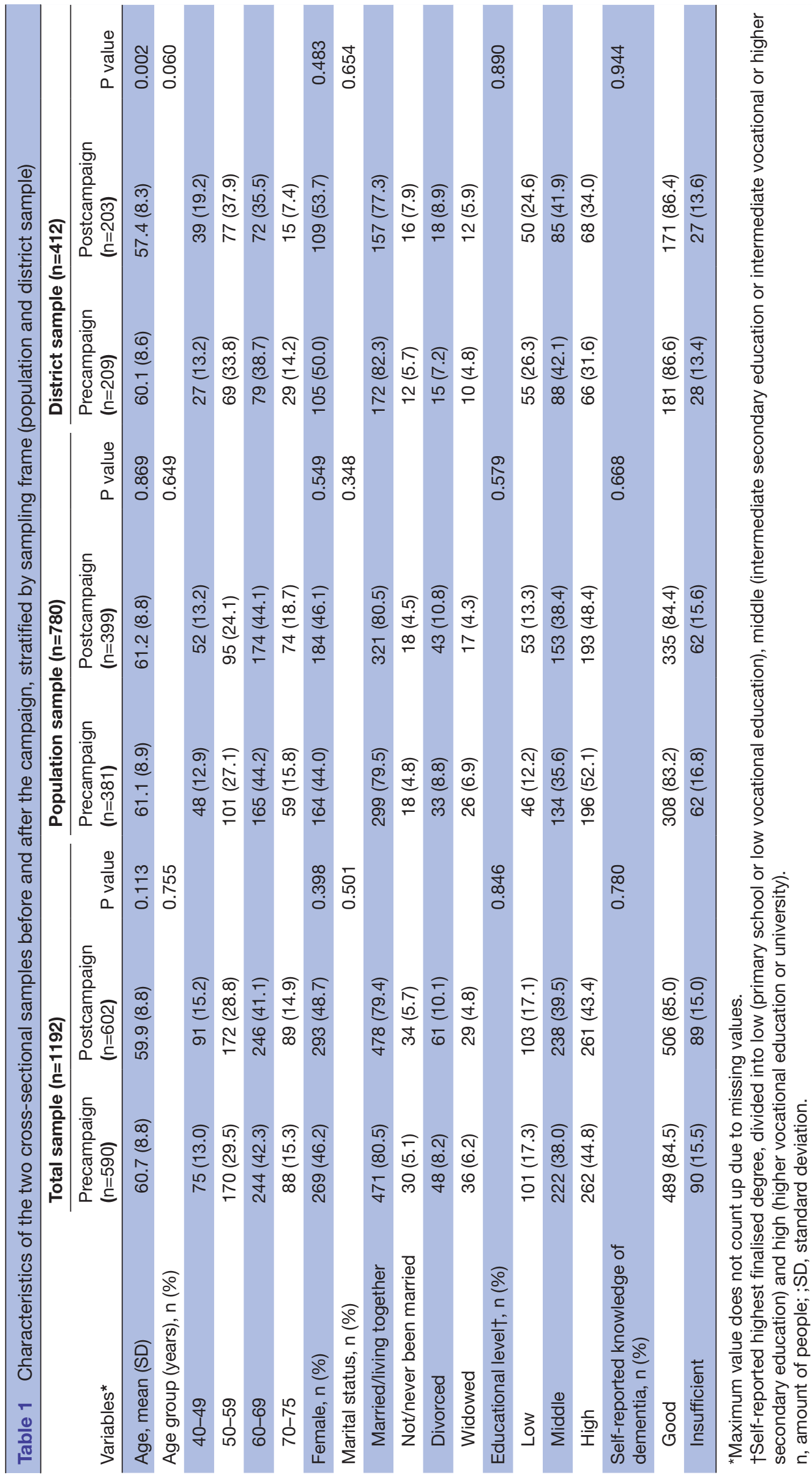


Box 1 Forms of community engagement during the campaign (March 2018 to January 2019)

Local engagement and support
More than 140 stakeholders (municipalities, schools, healthcare
centres, companies) committed to this campaign by distributing
campaign material/messages and/or organising public events.
Distribution of 35000 campaign leaflets and more than 1000 cam-
paign posters (at more than 400 locations within the Province).
Organisation of more than one public event per week ( $n=52$; lecture,
workshop or other community activities).
Campaign website
More than 10000 website visits.
Online campaign posters are downloaded more than 5500 times
in total.
Media
Over 65 media outlets (e.g. newspaper items, radio interviews).
Campaign tweets reached 200000 people.
Facebook messages reached more than 15000 people.
eHealth platform
9000 downloads of MijnBreincoach app.
Ministry of Health, Welfare and Sport in the Netherlands incorporat-
ed the app on their website on innovations in healthcare.

agreeing that dementia risk reduction is possible, and the percentage of participants identifying the three campaign themes. No difference in the primary outcome of awareness of dementia risk reduction was observed $\left(\mathrm{X}^{2}(1)=1.27, \mathrm{p}=0.260\right)$. Cognitive activity was identified most often as being protective against dementia at both preassessment (79.4\%) and postassessment (80.4\%), but there was no increase in awareness $\left(\mathrm{X}^{2}(1)=0.17\right.$, $\mathrm{p}=0.677)$. A modest increase in awareness was observed for physical activity $\left(7.6 \%\right.$ increase; $\left.\mathrm{X}^{2}(1)=7.48, \mathrm{p}=0.006\right)$ and healthy diet $\left(10.5 \%\right.$ increase; $\left.X^{2}(1)=12.37, \mathrm{p} \leq 0.001\right)$. More highly educated participants were more aware of dementia risk reduction compared with lower educated participants, both in the preassessment (low 18.2\%, middle $38.9 \%$, high $\left.59.4 \% ; \mathrm{X}^{2}(2)=53.46, \mathrm{p} \leq 0.001\right)$ and postassessment (low 29.3\%, middle $33.9 \%$, high $52.3 \%$; $\left.\mathrm{X}^{2}(2)=24.15, \mathrm{p} \leq 0.001\right)$. The same applies to the identification of the three campaign themes. In men, level of awareness decreased slightly with $8 \%\left(\mathrm{X}^{2}(1)=3.89\right.$, $\mathrm{p}=0.049$ ), but they identified the campaign theme 'eat healthy' more often over time $\left(\mathrm{X}^{2}(1)=10.99, \mathrm{p}=0.001\right)$. The level of awareness remained stable over time in women $\left(\mathrm{X}^{2}(1)=0.09, \mathrm{p}=0.770\right)$, participants under the age of 65 years $\left(\mathrm{X}^{2}(1)=0.78, \mathrm{p}=0.377\right)$ and participants aged 65 and above $\left(\mathrm{X}^{2}(1)=1.46, \mathrm{p}=0.227\right)$, but over time, the theme 'exercise regularly' was identified more often by participants under the age of 65 years $(9.4 \%$ increase; $\left.\mathrm{X}^{2}(1)=7.13, \mathrm{p}=0.008\right)$.

\section{Differences between the two campaign approaches}

No significant difference in level of awareness was found for both the population (from $47.1 \%$ to $40.5 \% ; \mathrm{X}^{2}(1)=3.39$, $\mathrm{p}=0.066)$ and district sample ( $39.9 \%$ to $42.7 \% ; \mathrm{X}^{2}(1)=0.33$, $\mathrm{p}=0.565)$. Compared with preassessment, cognitive

100

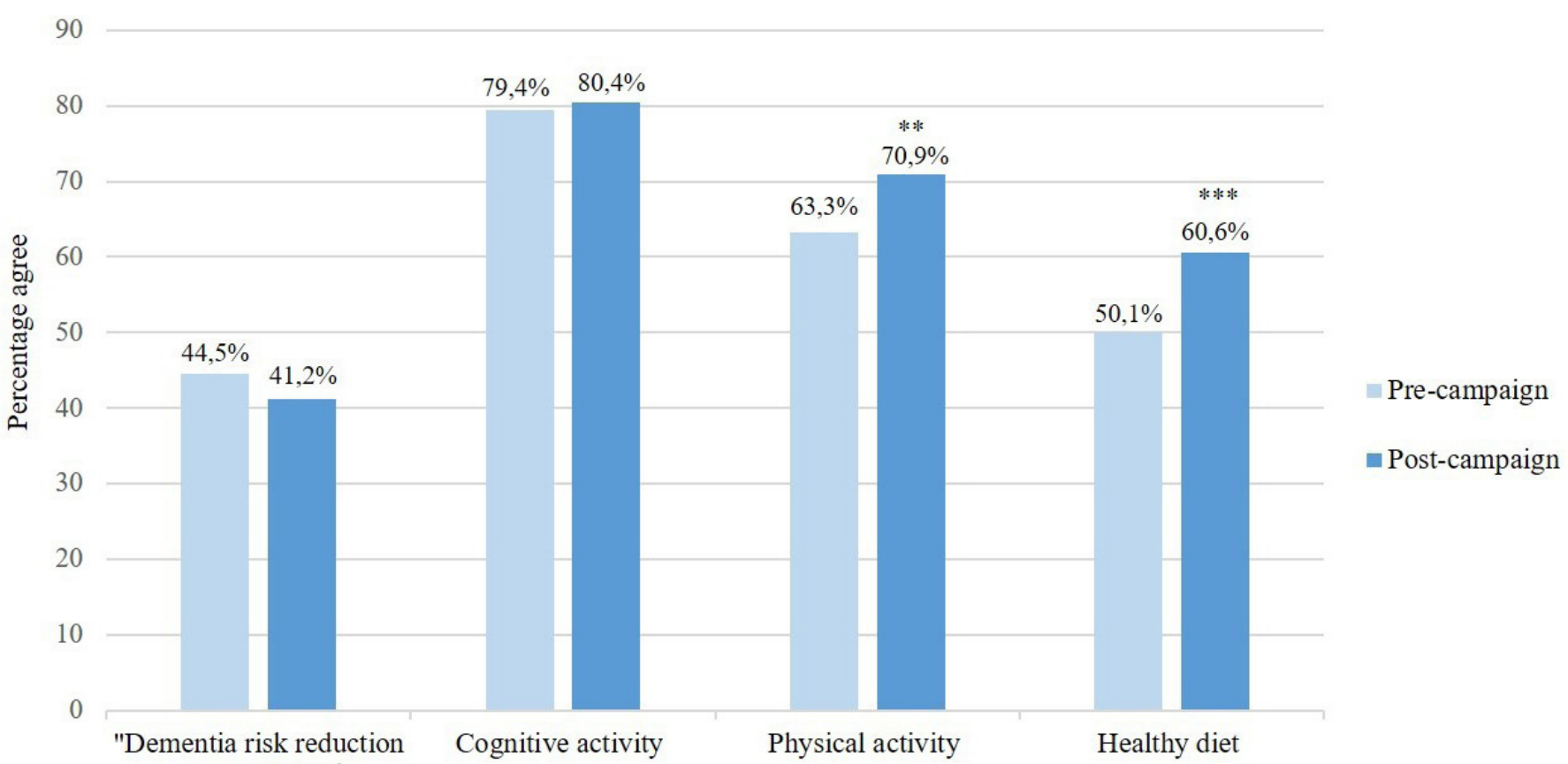

Figure 1 Precampaign $(n=590)$ and postcampaign $(n=602)$ comparison of the total sample. Percentage agreeing with the statement that dementia risk reduction is possible, and percentage identifying the three target risk factors/themes of the campaign. Maximum values and percentages do not count up due to missing values. ${ }^{1}$ Original statement presented to participants: 'There is nothing I can do to reduce my dementia risk'. ${ }^{* \star} \mathrm{p}<0.01 ;{ }^{* \star *} \mathrm{p}<0.001$. 
activity was not identified more often as a protective factor for dementia at postassessment, either in the population $\left(79.9 \%\right.$ to $\left.81.8 \% ; \mathrm{X}^{2}(1)=0.43, \mathrm{p}=0.510\right)$ or district sample $\left(78.5 \%\right.$ to $77.7 \%$; $\left.\mathrm{X}^{2}(1)=0.04, \mathrm{p}=0.844\right)$. Physical activity was identified more often in the population $(65.6 \%$ to $\left.73.3 \% ; \mathrm{X}^{2}(1)=5.14, \mathrm{p}=0.023\right)$, but not in the district sample $\left(59.2 \%\right.$ to $\left.66.3 \% ; \mathrm{X}^{2}(1)=2.17, \mathrm{p}=0.141\right)$. Healthy diet was identified more often in both the population (51.7\% to $\left.62.3 \% ; \mathrm{X}^{2}(1)=8.23, \mathrm{p}=0.004\right)$ and district sample $(47.3 \%$ to $\left.57.4 \% ; \mathrm{X}^{2}(1)=3.99, \mathrm{p}=0.046\right)$. An increase was found of the LIBRA factors low to moderate alcohol use $(26.9 \%$ to $\left.38.4 \% ; \mathrm{X}^{2}(1)=6.07, \mathrm{p}=0.014\right)$, obesity $(19.9 \%$ to $28.4 \%$; $\left.\mathrm{X}^{2}(1)=3.91, \mathrm{p}=0.048\right)$ and smoking $(29.3 \%$ to $42.9 \%$; $\left.\mathrm{X}^{2}(1)=8.15, \mathrm{p}=0.004\right)$ in the district sample. More highly educated participants were more aware of dementia risk reduction compared with lower educated participants, both in the preassessment (population low 13.7\%, middle $39.1 \%$, high $60.2 \% ; \mathrm{X}^{2}(2)=36.27, \mathrm{p} \leq 0.001$; districts low $21.8 \%$, middle $38.6 \%$, high $\left.56.9 \% ; \mathrm{X}^{2}(2)=15.41, \mathrm{p} \leq 0.001\right)$ and the postassessment (population low $31.4 \%$, middle $30.0 \%$, high $51.0 \% ; \mathrm{X}^{2}(2)=17.49, \mathrm{p} \leq 0.001$; districts low $27.1 \%$, middle $41.0 \%$, high $\left.55.9 \% ; X^{2}(2)=9.72, p=0.008\right)$. In those with a low level of education in the population, an increase in awareness of dementia risk reduction was observed $\left(17.7 \%\right.$ increase; $\left.\mathrm{X}^{2}(1)=4.18, \mathrm{p}=0.041\right)$, and for the campaign themes physical activity $(22.0 \%$ increase;
$\left.\mathrm{X}^{2}(1)=4.35, \mathrm{p}=0.037\right)$ and healthy $\operatorname{diet}(25.3 \%$ increase; $\left.\mathrm{X}^{2}(1)=5.79, \mathrm{p}=0.016\right)$.

Exposure to the campaign and level of awareness in the total postcampaign sample $(n=602)$

Awareness of dementia risk reduction was higher for postcampaign participants who reported to have heard compared with those who have not heard of the campaign $\left(51.4 \%\right.$ vs $37.9 \%$; $\left.\mathrm{X}^{2}(1)=6.52, \mathrm{p}=0.011\right)$, the campaign slogan $\left(53.3 \%\right.$ vs $\left.37.2 \% ; \mathrm{X}^{2}(1)=9.07, \mathrm{p}=0.003\right)$ and the eHealth platform ( $54.8 \%$ vs $36.6 \%$; $\mathrm{X}^{2}(1)=12.39$, $\mathrm{p} \leq 0.001)$. Campaign materials were more often recognised in the districts $(35.2 \%)$ than in the population sample $\left(26.8 \% ; \mathrm{X}^{2}(1)=3.92, \mathrm{p}=0.048\right)$. More than a third (37.2\%) expressed to have become more conscious of lifestyle being related to their brain health, and $30.4 \%$ stated to have engaged in a brain-healthy lifestyle. Physical activity $(45.8 \%)$, eating healthy $(40.9 \%)$ and weight management $(39.4 \%)$ were most often engaged in during the past year.

\section{Self-reported knowledge of dementia}

Figure 2 displays the level of awareness by self-reported general knowledge of dementia in the postassessment sample. Participants who stated that their general knowledge of dementia was considerable or good were more aware of dementia risk reduction than participants with

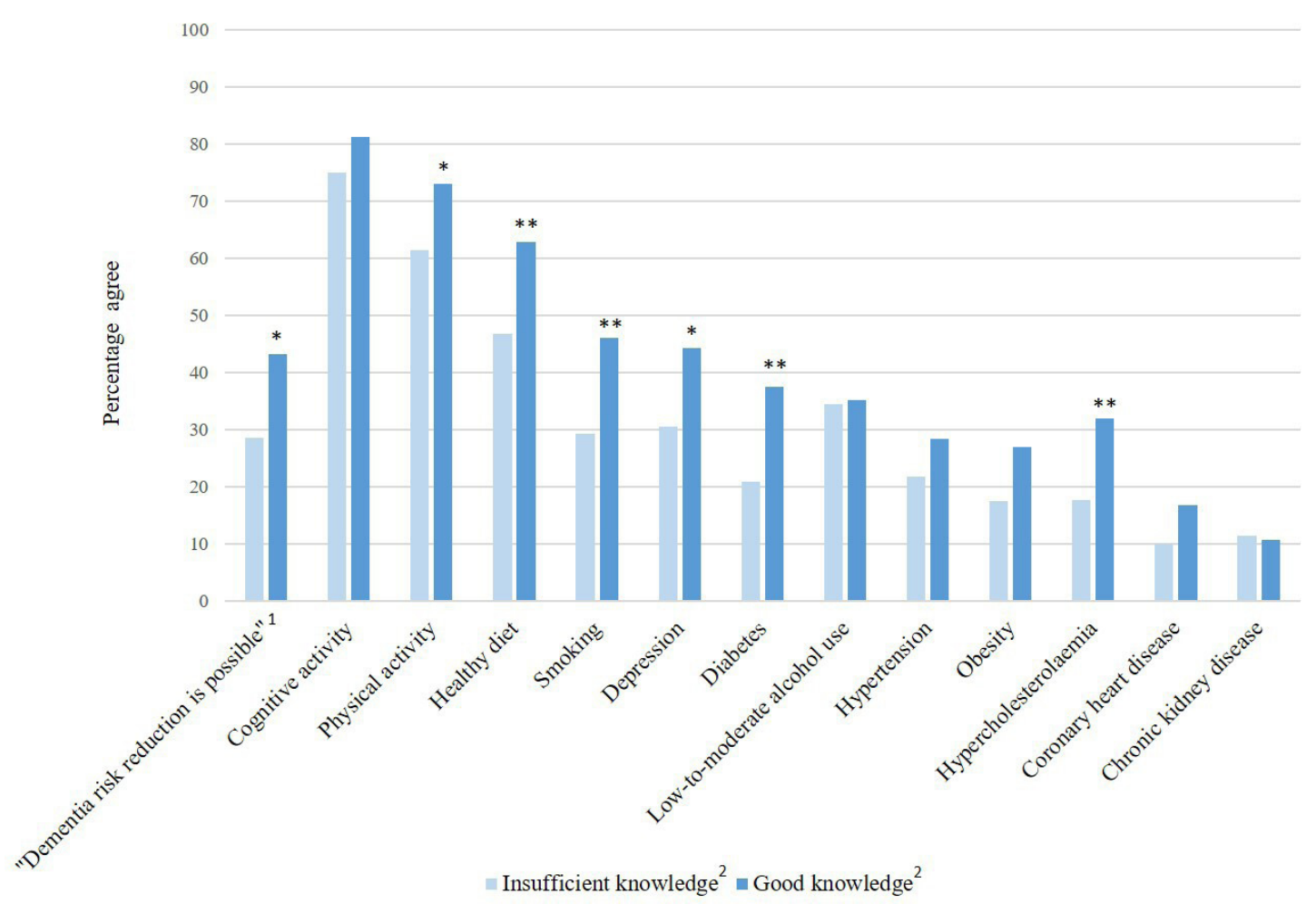

Figure 2 Level of awareness by self-reported general knowledge of dementia in the postassessment sample ( $\mathrm{n}=602)$. The percentages reflect the percentage of participants who agreed that a particular factor is a risk or protective factor for dementia. Maximum values and percentages do not count up due to missing values. ${ }^{1}$ Original statement presented to participants: 'There is nothing I can do to reduce my dementia risk'. 'Self-reported knowledge of dementia, divided into 'Insufficient knowledge' (answering options 'I don't know', 'Nothing at all' and 'Not very much') and 'Good knowledge' ('Some', 'Quite a lot' and 'A great deal'). ${ }^{*} \mathrm{P}<0.05 ;{ }^{* *} \mathrm{p}<0.01$. 
self-reported insufficient general knowledge $\left(\mathrm{X}^{2}(1)=6.48\right.$, $\mathrm{p}=0.011$ ). The same applied to the identification of the risk/protective factors physical activity $\left(\mathrm{X}^{2}(1)=4.59\right.$, $\mathrm{p}=0.032)$, healthy diet $\left(\mathrm{X}^{2}(1)=7.32, \mathrm{p}=0.007\right)$, smoking $\left(\mathrm{X}^{2}(1)=8.18, \mathrm{p}=0.004\right)$, depression $\left(\mathrm{X}^{2}(1)=5.44, \mathrm{p}=0.020\right)$, diabetes $\left(\mathrm{X}^{2}(1)=8.31, \mathrm{p}=0.004\right)$ and hypercholesterolaemia $\left(\mathrm{X}^{2}(1)=6.60, \mathrm{p}=0.010\right)$.

\section{The eHealth platform}

Anonymous user tracking showed that the 12-item 'quick test' was completed more than 13300 times by people from the general public during the campaign. The mean age of this group was 57 years (SD 14.3; range 18-94 years), $68 \%$ were female and $76 \%$ were higher educated (i.e. higher vocational education or university). Room for improvement (according to self-reported presence or absence of risk/protective factors) was highest for the LIBRA factors hypertension, hypercholesterolaemia and alcohol consumption. Almost 36\% $(n=4755)$ created an account and completed the more comprehensive administration (mean age 57 years, $72 \%$ female, $78 \%$ higher educated). Room for improvement, based on the extensive LIBRA administration using validated questionnaires, was highest for physical inactivity, adherence to a Mediterranean diet and cognitive activity. These were also the factors that were chosen most often for receiving daily notifications.

\section{DISCUSSION}

This paper presents the results of the first health promotion campaign in the Netherlands aimed at increasing awareness of dementia risk reduction in middle-aged, community-dwelling individuals. In general, this study was not successful since no population-level change in awareness was observed. However, two out of the three campaign themes were identified more often after the campaign. People exposed to the campaign, its slogan and the eHealth platform were significantly more aware of dementia risk reduction and the three campaign themes. Participants from the district campaign recognised campaign material and the eHealth platform more often.

Unfortunately, awareness of dementia risk reduction and knowledge of most LIBRA factors did not increase. Several reasons might exist. This campaign did not use national mass media, in contrast to a population-based awareness campaign in Ireland that did find a significant increase in awareness of dementia risk reduction. ${ }^{30}$ Due to a limited budget and resources, the coverage of our campaign might have been insufficient to reach population-level increase in awareness. Interestingly, our study did find an increase in awareness in those who reported to have been exposed to the campaign, while the Irish study could not differentiate between the exposed and non-exposed groups. ${ }^{30}$ Women stated more often than men to be exposed to our campaign material and to have visited the eHealth platform, which is in line with previous studies stating that women participate more than men in health campaigns. ${ }^{35}$ However, this did not translate in an increase in awareness in women at postassessment. In addition, it could be that the statement to assess awareness was too complex ('there is nothing I can do to reduce my dementia risk'). A simpler, positively formulated statement might have been more suitable for our purpose. The statement used was taken from the BSA $2015^{19}$ in order to compare dementia literacy between the UK and the Netherlands. Furthermore, there was no higher endorsement of the protective factor of cognitive activity after the campaign. This might be explained by a ceiling effect, as many people already considered it to be a protective factor at baseline.

Strengths of this study include the extensive precampaign and postcampaign surveys, in which we used multiple items to assess awareness of dementia risk reduction in general, and specific risk and protective factors. Furthermore, we used large independent samples and comparable methodology to a previous study assessing awareness of dementia risk reduction. ${ }^{19}$ Next, the intervention part (awareness campaign) of this study was designed in consultation of experts, addressed, in line with the WHO guidelines, ${ }^{5}$ multiple dementia risk factors and collaborated with stakeholders in a multidisciplinary approach. ${ }^{5}$ The involvement of stakeholders created a 'snowball effect', as they communicated the campaign message via their own channels (see box 1). Also, although the basic framework was set beforehand, the flexible design of the campaign made it possible to alter strategies along the way.

This study, however, also had limitations. First, this study was not inclusive regarding non-Dutch-speaking individuals and individuals without internet access. Furthermore, the population samples were drawn from participants from a previous survey interested in future research. This could have led to a preselection of people interested in scientific research and health. Last, the restrained resources of the team (e.g. to contact relevant stakeholders) limited the reach and effect of the campaign. These limitations were already acknowledged beforehand. This campaign was developed as a proofof-concept study in a naturalistic setting, investigating campaign strategies and the extent of involvement of the community.

\section{Recommendations for future campaigns}

In general, involvement of the community is an important determinant of success. Further, as this study shows that individuals with self-reported sufficient knowledge of dementia are more aware of dementia risk reduction, it is recommended to incorporate such a campaign into a general dementia campaign, or even a broad health promotion campaign, given the overlapping risk factors for cardiovascular disease and diabetes. In fact, incorporating lifestyle recommendations of various noncommunicable diseases is one of the recommendations of the WHO. ${ }^{5}$ Furthermore, it is important to tailor health messages to specific subgroups (e.g. based on educational 
level, age, sex, high/low-risk group). Their needs, wishes and barriers to engage in a brain-healthy lifestyle should be further explored, both prior to the execution of a campaign and as a postcampaign evaluation, for example, by qualitative research. To illustrate, comparable to earlier studies, ${ }^{22-24}$ our study showed that dementia risk reduction literacy was higher in more highly educated participants. However, campaign material was recognised more often and awareness only improved in the lower educated group (particularly in the population sample). The campaign was designed with differences in health literacy and socioeconomic status in mind (e.g. content checking by the MHS). Also, it was striking that campaign activities (e.g. lectures, workshops) were particularly visited by the older half (60-75 years) of the targeted population, despite our efforts in providing information online and using terms as 'brain health' instead of 'dementia risk'. Reaching younger individuals, with a positively framed message on the potential of dementia risk reduction, is important to take into consideration. Next, it should be noted that increasing awareness is an essential yet insufficient step towards behavioural change. Altering complex and entrenched behaviours is very difficult, and unlikely to be sufficiently affected by this small-scale campaign. This was done to some extent by prompting people with low-level, positive messages on how to engage in brainhealthy activities. Yet, the main focus of this campaign was increasing awareness and not behavioural change.

\section{CONCLUSION}

This study was not able to reach a population-level increase of awareness of dementia risk reduction, but did increase awareness and willingness to take action in those exposed. Future campaigns should scale up to maximise exposure and engagement in the population. More insight is needed on how increasing awareness may trigger lifestyle behaviour.

Acknowledgements We thank all the participants, the municipal health services of North and South Limburg and the municipality of Roermond for their support in carrying out the survey. We thank Zuiderlicht, Betawerk, Sananet, the Department of Health Promotion of Maastricht University, the Dutch Alzheimer's Association, the Dutch Brain Foundation, Actiecentrum Limburg Positief Gezond and all other 'campaign friends' for their consultation and contributions to this project.

Contributors $\mathrm{IH}$ : study design, data collection, data analysis and interpretation, drafting the manuscript. SK, MvB, MdV, FRV: study design, critical revision of the manuscript. KH: data collection, critical revision of the manuscript. KD: study design, data collection, data analysis and interpretation, study supervision.

Funding This study was supported by the Province of Limburg (registration number: SAS-2015-04931) and the Health Foundation Limburg.

Disclaimer The funders had no role in study design, in the collection, analysis and interpretation of data, in the writing of the report, and in the decision to submit the paper for publication.

Competing interests None declared.

Patient consent for publication Not required.

Ethics approval The Ethics Review Committee Psychology and Neuroscience of Maastricht University approved this study (reference number 177-07-03-2017). All participants received an information letter and signed a digital informed consent form prior to participation.
Provenance and peer review Not commissioned; externally peer reviewed.

Data availability statement Data are available upon reasonable request. The data set and statistical code are available upon reasonable request. No additional data available.

Supplemental material This content has been supplied by the author(s). It has not been vetted by BMJ Publishing Group Limited (BMJ) and may not have been peer-reviewed. Any opinions or recommendations discussed are solely those of the author(s) and are not endorsed by BMJ. BMJ disclaims all liability and responsibility arising from any reliance placed on the content. Where the content includes any translated material, BMJ does not warrant the accuracy and reliability of the translations (including but not limited to local regulations, clinical guidelines, terminology, drug names and drug dosages), and is not responsible for any error and/or omissions arising from translation and adaptation or otherwise.

Open access This is an open access article distributed in accordance with the Creative Commons Attribution Non Commercial (CC BY-NC 4.0) license, which permits others to distribute, remix, adapt, build upon this work non-commercially, and license their derivative works on different terms, provided the original work is properly cited, appropriate credit is given, any changes made indicated, and the use is non-commercial. See: http://creativecommons.org/licenses/by-nc/4.0/.

ORCID iD

Irene Heger http://orcid.org/0000-0002-2083-7890

\section{REFERENCES}

1 Livingston G, Sommerlad A, Orgeta V, et al. Dementia prevention, intervention, and care. Lancet 2017;390:2673-734.

2 Patterson C. World Alzheimer report 2018. London: Alzheimer's Disease International, 2018.

3 Lincoln P, Fenton K, Alessi C, et al. The Blackfriars consensus on brain health and dementia. Lancet 2014;383:1805-6.

4 Norton S, Matthews FE, Barnes DE, et al. Potential for primary prevention of Alzheimer's disease: an analysis of population-based data. Lancet Neurol 2014;13:788-94.

5 World Health Organization. Risk reduction of cognitive decline and dementia: WHO guidelines. Geneva, 2019.

6 Ngandu T, Lehtisalo J, Solomon A, et al. A 2 year multidomain intervention of diet, exercise, cognitive training, and vascular risk monitoring versus control to prevent cognitive decline in at-risk elderly people (finger): a randomised controlled trial. Lancet 2015;385:2255-63.

7 Moll van Charante EP, Richard E, Eurelings LS, et al. Effectiveness of a 6-year multidomain vascular care intervention to prevent dementia (preDIVA): a cluster-randomised controlled trial. Lancet 2016;388:797-805.

8 Andrieu S, Guyonnet S, Coley N, et al. Effect of long-term omega 3 polyunsaturated fatty acid supplementation with or without multidomain intervention on cognitive function in elderly adults with memory complaints (MAPT): a randomised, placebo-controlled trial. Lancet Neurol 2017;16:377-89.

9 Kivipelto M, Ngandu T, Laatikainen T, et al. Risk score for the prediction of dementia risk in 20 years among middle aged people: a longitudinal, population-based study. Lancet Neurol 2006;5:735-41.

10 Rosenberg A, Ngandu T, Rusanen M, et al. Multidomain lifestyle intervention benefits a large elderly population at risk for cognitive decline and dementia regardless of baseline characteristics: the finger trial. Alzheimers Dement 2018;14:263-70.

11 Kivipelto M, Mangialasche F, Ngandu T. Lifestyle interventions to prevent cognitive impairment, dementia and Alzheimer disease. Nat Rev Neurol 2018;14:653-66.

12 Deckers K, Köhler S, van Boxtel M, et al. Lack of associations between modifiable risk factors and dementia in the very old: findings from the Cambridge City over-75s cohort study. Aging Ment Health 2018;22:1272-8.

13 Vos SJB, van Boxtel MPJ, Schiepers OJG, et al. Modifiable Risk Factors for Prevention of Dementia in Midlife, Late Life and the Oldest-Old: Validation of the LIBRA Index. J Alzheimers Dis 2017:58:537-47.

14 Prince M, Ali G-C, Guerchet M, et al. Recent global trends in the prevalence and incidence of dementia, and survival with dementia. Alzheimers Res Ther 2016;8:23.

15 Roehr S, Pabst A, Luck T, et al. Is dementia incidence declining in high-income countries? A systematic review and meta-analysis. Clin Epidemiol 2018;10:1233-47.

16 Satizabal CL, Beiser AS, Chouraki V, et al. Incidence of dementia over three decades in the Framingham heart study. N Engl J Med 2016;374:523-32. 
17 Livingston G, Huntley J, Sommerlad A, et al. Dementia prevention, intervention, and care: 2020 report of the Lancet Commission. Lancet 2020;396:413-46.

18 Heger I, Deckers K, van Boxtel M, et al. Dementia awareness and risk perception in middle-aged and older individuals: baseline results of the MijnBreincoach survey on the association between lifestyle and brain health. BMC Public Health 2019;19:678.

19 Marcinkiewicz A, Reid S. Attitudes to dementia: findings from the 2016 British social attitudes survey London. NatCen Social Research, 2016.

20 Cations M, Radisic G, Crotty M, et al. What does the general public understand about prevention and treatment of dementia? A systematic review of population-based surveys. PLoS One 2018;13:e0196085.

21 Liu D, Cheng G, An L, et al. Public knowledge about dementia in China: a national WeChat-Based survey. Int J Environ Res Public Health 2019;16:4231.

22 de Veer AJE, Peeters JM, Brabers AEM, et al. Determinants of the intention to use e-health by community dwelling older people. BMC Health Serv Res 2015;15:103.

23 Eakin EG, Bull SS, Glasgow RE, et al. Reaching those most in need: a review of diabetes self-management interventions in disadvantaged populations. Diabetes Metab Res Rev 2002;18:26-35

24 Luten KA, Dijkstra A, de Winter AF, et al. Developing a communitybased intervention for Dutch older adults in a socioeconomically disadvantaged community. Health Promot Int 2019;34:567-80.

25 Askari N, Bilbrey AC, Garcia Ruiz I, et al. Dementia awareness campaign in the Latino community: a novel community engagement pilot training program with Promotoras. Clin Gerontol 2018;41:200-8.
26 Moorhouse P, Hamilton LM. Not if, but when: impact of a driving and dementia awareness and education campaign for primary care physicians. Can Geriatr J 2014;17:70-5.

27 Kim S, Werner P, Richardson A, et al. Dementia stigma reduction (deserve): study protocol for a randomized controlled trial of an online intervention program to reduce dementia-related public stigma. Contemp Clin Trials Commun 2019;14:100351.

28 Werner P, Kermel Schiffman I, Schiffman K I. Exposure to a national multimedia Alzheimer's disease awareness campaign: assessing stigmatic beliefs towards persons with the disease. Int J Geriatr Psychiatry 2018;33:e336-42.

29 Farrow M. User perceptions of a dementia risk reduction website and its promotion of behavior change. JMIR Res Protoc 2013;2:e15.

30 Hickey D. The impact of a national public awareness campaign on dementia knowledge and help-seeking intention in Ireland. Dublin: Health Service Executive, 2019.

31 CBS. Centraal bureau voor Statistiek (CBS) Statline. Available: https://opendata.cbs.nl/statline/\#/CBS/nl/dataset/03759ned/table? $\mathrm{dl}=26570$ [Accessed 12 Sep 2019].

32 We zijn zelf het medicijn. Campaign website. Available: https://www. wezijnzelfhetmedicijn.nl/ [Accessed 19 Dec 2019].

33 MijnBreincoach. Online platform MijnBreincoach. Available: https:// www.mijnbreincoach.eu/ [Accessed 19 Dec 2019].

34 Deckers K, van Boxtel MPJ, Schiepers OJG, et al. Target risk factors for dementia prevention: a systematic review and Delphi consensus study on the evidence from observational studies. Int J Geriatr Psychiatry 2015;30:234-46

35 Compernolle S, De Cocker K, Lakerveld J, et al. A RE-AIM evaluation of evidence-based multi-level interventions to improve obesityrelated behaviours in adults: a systematic review (the spotlight project). Int J Behav Nutr Phys Act 2014;11:147. 